\title{
Re-charting Architecture or the End of "Architecture" as We Know It?
}

\author{
Ilya Fadjar Maharika, ${ }^{1, *}$ \\ ${ }^{1}$ Universitas Islam Indonesia, Indonesia
}

\begin{abstract}
As a discipline, the exchange of ideas between architecture and other disciplines or subject areas occurs as a rule rather than an exception. In an attempt to re-chart architecture, mapping the exchange may give a more complete picture as a reflection of architecture itself. In doing so, a survey of the use of the word "architecture" was carried out. Scopus.com was used extensively to explore articles using the word in their abstract, keyword, or title. The finding shows that the word "architecture" is extensively used in nearly all subject areas in Scopus stretching the meaning of architecture to its widest as the organization of things. That "Architecture" itself seems to be diminishing leads to more questions particularly regarding Architectural Education 4.0.
\end{abstract}

Keywords: Scopus, information technology, Architectural Education 4.0

\section{Introduction}

Elizabeth Grosz's writing "Architecture from the Outside" (2001) has alerted us to the position of architecture and its outside. This "outsideness" is not about designing architecture from building envelope inward or space between building in urban context, but rather from outside of architecture as a discipline. For Grosz, as a philosopher, thinking about architecture from the outside is to spark architecture to "think." For her, the outside is capable of a lot of positivity and innovation. Hence, architecture has that opportunity as well if we try to confront it from the outside, from other disciplines. From this point of view, as Grosz has understood, and also perhaps as architects and architecture scholars have agreed, architecture is commonly thought of and conceived as an art and a science of manipulation of space, and at large, a systematic and powerful model for spatial organization and modification (Grosz, 2010: 108-9).

The purpose of this paper is to re-chart architecture. In doing so, the position of architecture itself needs to be interrogated. It is precisely in this position, that what Grosz has posited architecture vis a vis its outside that may induce something new, a new chart of architecture. However, unlike Grosz who talks about architecture as an outsider, this position will differ, as the author is both an architect and architecture educator. Architecture by its nature is a porous body of knowledge. This porosity makes the flow of ideas between the inside (of architecture) and outside (as other discipline or subject areas) as the rule rather than exception. Although accepted by scholars in architectural fields as well as architects, the influence of other disciplines in the architectural body of knowledge, there is little attention paid as to how this flow of knowledge happens. There is little understanding whether architecture may influence these other subjects and then perhaps the influence is cycling back to reshape architectural knowledge.

This paper tries to give an insight into this flow of ideas that form a continuous dynamic in shaping and reshaping architecture. Perhaps this back and forth of ideas also gives an overview of the overall discourse of architecture creating somewhat a chart or re-chart of the knowledge of architecture.

Furthermore, since the context of this re-charting is in the domain of education, it is necessary to look at the newest trends and challenges in education, namely Education 4.0. Induced by the Industrial Revolution 4.0 where information becomes a wild token of change, many believe that it will also change the manufacturing process, value chain, distribution and customer service processes, as well as a wide range of the utilization of the Internet of Things (IoT). In higher education, the rise of MOOCs (Massive Open Online Course), the need for global identity and "education for you" will push forward the paradigm of student-centered learning and allow students to manufacture their interests for their future careers. The change will certainly reshape the business of higher education (Asmaa AbuMezied, n.d.).

Thus, it is also necessary, especially for architectural education, to understand how information and information technology may influence architectural knowledge and practices. Currently, we have exposed the flow of information to which ideas may transfer from one discipline to another in much more dynamic ways. Hence, it is also an interesting view into how information and computer technology have shaped architecture and vice versa. Indeed, since the term 're-charting' itself is a vague delineation of a task specifically dealing with the flow of ideas created by the porosity of architecture itself, it is necessary to limit ourselves through the question we deal with.

Thus, the question will be twofold. The first is the relation between architecture and its outside. The questions arisen

Corresponding author: maharika@uii.ac.id 
will be such as what kind of disciplines or subject areas of knowledge have an exchange of ideas with architecture? Do they change architecture or vice versa? What aspects and what kind of impact does this exchange of influence have on architecture and to architecture education? The second is on the specific relationship between architecture and information especially the information technology that shapes the current Industrial Revolution 4.0. The question may be escalated to what impact does information technology have on architecture and architecture education.

Of course, not all of our question will be or are able to be answered easily in this short paper. The proposed methodology does address the limitation of this research.

\section{Mapping The Inquiry: Strategy}

In an attempt to examine and then limit the scope in addressing these questions, the strategy of inquiry is proposed. In this paper, the author will use the term Architecture for "architecture" that is commonly understood as conventional line of thought of architecture by architects (or what is being taught in architecture schools). Hence, strategically speaking, this paper will use a literature exploration and survey to identify the use of architecture in many other disciplines represented in the articles. As Wang and Groat have believed, the literature contains historical lineage showing a reservoir of historical information. It also shows genetic link and roots with an idea in the background. Exploring literature gives an understanding of the conceptual landscape in its contemporary context, the vantage point that create nuance, and of the intellectual agenda behind (Groat, L, and Wang, D. 2002: 58). Consequently, it may situate Architecture as a discipline in front of challenges from other disciplines.

In term of tactics of this exploration, since a thorough survey is impossible; the author has limited the primary source and tools to Scopus (Scopus.com). For initial information about the extent of this survey, Scopus was searched using the keyword "architecture" in the article title, abstract, and keywords. It reaches 693,114 documents. There are 138,806 documents using the word "architecture" in their title and 321,279 documents that use it as a keyword (search date started October 4 - 20, 2017, some inconsistency of this number may appear due to the dynamic nature of the Scopus record).

Indeed, the choice of Scopus itself creates somewhat of a bias in favor of natural sciences, engineering and biomedical research, impairing social sciences, arts and humanities let alone architecture (Mongeon, P., \& Paul-Hus, A., 2015). Scopus also declines many Architecture magazines - which to architects are vital. But since the purpose of this paper is to expand Architecture through the outside, the bias itself perhaps is an advantage that create windows of opportunity to find a novel perspective on how the ideas of architecture are being developed over the course of time, place and subjects to reveal what Grosz has stated as positivity and innovation.

\section{Cross-disciplinary Use of "Architecture"}

The word "architecture" has reached many disciplines and subject areas. For the purpose of this paper, the author starts from documents that use architecture in title, abstract, and keywords and then narrows it down to documents that use architecture in their keywords. The survey was also narrowed down to the "only article" type of documents. At this initial mapping, it showed 111,580 articles (search date 16 October 2017). Based on these numbers, the analysis available in Scopus is used to create an overview of this expanding chart of architecture.

Seen from the disciplinary use of architecture, the overall picture of the articles in Scopus can be seen from its subject areas in Fig. 1.

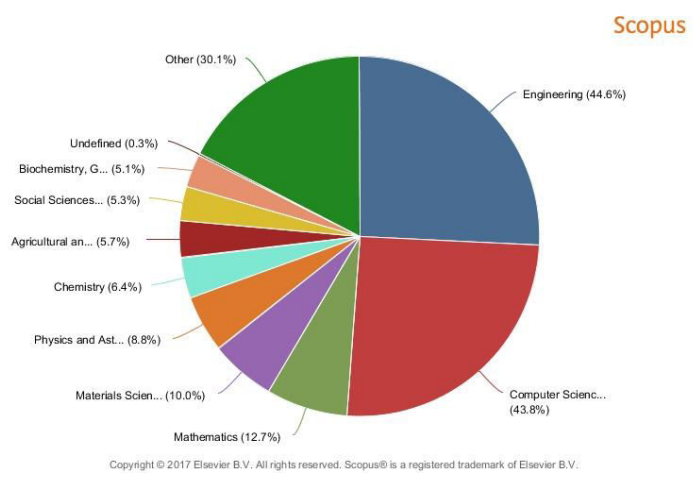

Fig. 1. Number of articles in Scopus per subject area. Source: Scopus.com, date of searching 16 October 2017.

Currently, from the chart of Fig. 1, we see that the fields using the word architecture in their keyword extensively is primarily engineering (44.6\%) and then computer science (43.8\%). Surprisingly only 3128 articles in "art and humanities" which are generally the "host" of Architecture is in the chart included in the "other" (30.1\%).

Seeing the source of this Scopus data, most of the journals come from computer science. There are three top sources, namely Lecture Notes in Computer Science (Springer Verlag, 1885 articles), IEEE Transactions on Computers (EEE Computer Society, 1123 articles), and IEEE Transactions on Very Large-Scale Integration (VLSI) Systems (Institute of Electrical and Electronics Engineers Inc. with 746 articles). The architectural journals listed are $A R Q$ (Pontificia Universidad Catolica de Chile, 191 articles) and Architectural Record (McGraw-Hill Construction Dodge with the contribution of 125 articles).

Seen from the "historical" use of architecture in Scopus, Fig. 2 shows a dramatic increase in the last 20 years only. 


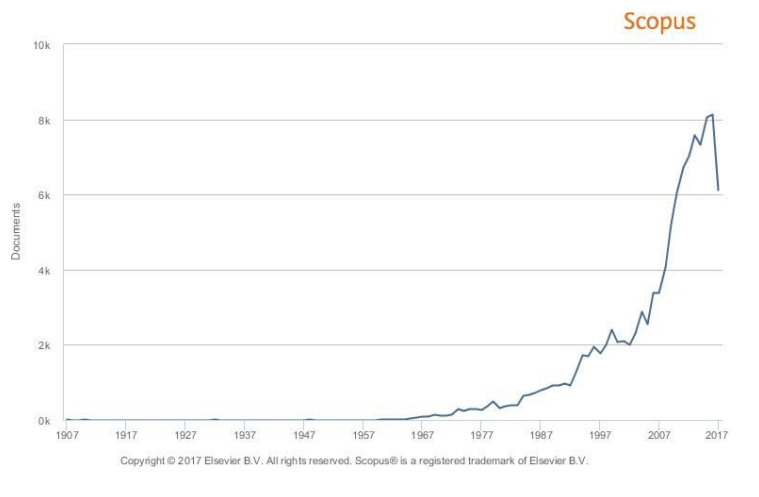

Fig. 2. Number of article in Scopus per year.

Source: Scopus.com, search date 16 October 2017.

In fact, the use of architecture in Scopus seems to have expanded only very recently. The numbers in the chart (Fig. 2) shows that the first record is in the year 1907 with only a small number of papers and then increases in the 1970s and a rapid increase after the year 2000. From 1907 to 1950 there were only five articles covering medicine ( 3 articles), arts and humanities, and psychology as well as an undefined area regarding animal behavior (Mowrer, 1932). The total amount of papers from the earliest recorded until 1969 was only 104 or 7.4 articles per year. After 1970, the number increased reaching 24,214, or an average of 807 articles per year. After 2000 , the number increases dramatically as it reaches 87,249 articles with an average of 4,847 articles per year marking the widest use of the term "architecture" in the scientific world.

Which discipline dominates the contribution use of architecture can be seen from the composition of subject areas. As a 'timeline' of architecture, from 1951 to 1970, the composition of subject areas that used architecture in their keywords changed radically. There were 586 articles, $80.2 \%$ of them from the field of medicine, followed by engineering (7.2\%) and social science (4.4\%), and then by dentistry (3.8\%) and health professions $(3,6 \%)$, computer science reached only $1.4 \%$, ranked $10^{\text {th }}$ on the list. A Picture of 1971 to 1980 shows a dramatic change as well. From 2,759 articles, the five largest compositions of subjects are engineering $(69.8 \%)$, and then medicine $(15.7 \%)$, computer science $(11.9 \%)$, mathematics $(12.7 \%)$ and nursing $(1.8 \%)$. The rise of computer science in this era is evident.

In the decade 1981-1990, the field of engineering is still in the forefront as it reaches $64.4 \%$, followed by computer science $38.0 \%$ and mathematics (12.5\%). Rather surprising, physics and astronomy comes in fourth place (7.2\%), followed by the ever-existent subject of medicine $(6.0 \%)$.

There is no significant change in the following decade, 1991-2000, as the big three were still engineering (51.8\%), computer science $(50.4 \%)$, and mathematics (12\%). A swap appears between medicine $(5.1 \%)$ in the fourth and physics and astronomy $(5.1 \%)$ comes in fifth place. However, the years 2001-2010 mark the first-time computer science $(47.8 \%)$ took a lead replacing engineering (40.5\%), which placed second and medicine lost its position in the top five. It dropped to the $11^{\text {th }}$ position. Then material science $(8.3 \%)$ entered the list of the big five as well as physics and astronomy (7.6\%). Since then, in the last decade of 2011 to the present (2017), material science is in third place after computer science (41.8\%), engineering (41.3\%) and material science $(14.5 \%)$ as the big three followed by mathematics $(11.8 \%)$ and physics and astronomy $(11.6 \%)$.

\section{Ideas Exchanged Through The Use of Architecture}

While it would be too difficult in this paper to reveal all ideas behind the use of architecture in all Scopus indexed articles within the range of time in detail, what has been pinpointed is the "interesting" use of architecture that may give indication of new discourse for Architecture. Again, using the tactic of making a historical time line of thematic use of architecture it perhaps indicates the idea exchanged between the field of Architecture and other disciplines that use architecture and how it has evolved.

The oldest article in Scopus was in 1907 in the field of psychology addressing an experiment on the aesthetic value of architecture and design. Commenting on his original paper, Rowland explains how observers had difference introspections and ways of enjoying decorative design characterized by opposing demands of art as well as of life (Rowland, 1907).

The second oldest was in the field of health care. Ziemer (1910) addressed a history of the medical research group, the Mayo Clinic. The first time the word "information" appears in the keyword to mention the information center at the Mayo Clinic. Since the document shows only limited information, it seems that the document lists one of the oldest clinics in the United States of America, which has now become a global center of "hope and healing" (Mayo Clinic History \& Heritage, n.d.).

After over twenty years, the third oldest article appeared in 1932, in the field of psychology. Instead of writing about architecture in our current sense, it addresses the "animal architecture" of a rooster. The architecture here points rather to the shape of animal kingdom (Mowrer, 1932).

The term architecture appears in a journal of medicine entitled School Architecture (1945). It is not entirely clear in what way the term was used since there is only very limited information, but interestingly, also in the year 1945, the notion of "biophilic architecture" appears, potentially for the first time. However, it is not from the field of what we now familiar with, the biophylic form of Architecture for instance, but from the field of medicine addressing the molecular architecture of cells (Leake, 1948). From this point, we see that the idea from other field may reoccur in Architecture if a supporting factor is "ready." In the case of the biophylic form of Architecture, today's expression of architecture of cells as real building is possible due to computer technology and parametric programming.

In the 1960s, many publications that use architecture are addressed on the topic of health. It is expressed extensively on the principles of design of housing that appeared in the medicine journal Royal Society of Health Journal (Hutchings, 1960). Furthermore, in 1961, three papers appeared all addressing architecture and its relationship with health. Gottlieb (1961) outlines the history of western medicine, especially the temples and hospital sites in the citystate of Epidaurus where the shrine Asklepios was devoted to the gods of medicine. In the current situation, the temple is regarded as a world heritage site due to its valuable insight 
into the healing cults of the Greek and Roman eras (UNESCO, n.d.). The relationship between material and health was addressed by Kolmovskoi (1961) mentioning glass as a hygienic construction material. A deeper understanding of the relationship between human health and its environment was also outlined in the context of the office environment in the Journal of Occupational Medicine. In the paper, it is mentioned, perhaps, for the first time, the terms human-engineering and bioengineering (Gad, 1961). In 1962, there were six articles all in the context of sanitation, medicine, and health including attention to hospitals and space perception in the ocular field. In 1963, there were 19 documents and in 1964, 16 documents about medical and public health facilities such as Space Planning Principles for Biomedical Research Laboratories (Snow 1963). In 1964, the name of Frank Lloyd Write appeared in a psychoanalytic interpretation of his designs (Globus, G. G., \& Gilbert, J., 1964). In 1965, 49 documents were published also in the medicine field, especially on oral and dental hygiene. In 1966 there were 60 documents also published in medicine including from the Journal of Archaeology addressing The Hospice of the Knights of St. John in Akko (Goldmann, Z. 1966). A further 92 documents were published in 1967.

Although health and medicine become a central theme of publication in the early records using architecture, the central theme of these early years was sanitation and hygiene. However, between 1965 and 1970 many of the publications in that domain shifted to specific factions, namely in dentistry, such as surgery space, dental offices, and the like.

From a general point of view, in this initial exchange of ideas, it seems that the use of architecture is primarily speaking of buildings that facilitate medical needs. There is also the use of architecture in terms of its metaphorical meaning such as the "architecture of behavior" in psychology although it was still very limited. The notion of biophilic architecture was also being introduced, albeit for cells, which today is known as the embryonic ideas of current trends.

The survey of the early years of Scopus finds small numbers of articles making it possible to inspect their content rather in detail. After the 1970s, we are unable to investigate in more detail in each article as the numbers grow significantly. Hence, we expose only the field or subject areas and pinpoint certain specific articles containing novelty in the use of architecture, or which have considerable citations or addressing specific issue or interest.

In the early 1970s, we also encounter the word of architecture used for the first time in computer science. New concepts arrived, as shown by 124 documents published containing words such as 'operating system architecture' or 'new architecture for mini computers.' In the abstract, the word architecture was used to mention the context of the new science of computers such as the 'architecture of the system.' There was also mention of the role of the architect in the field of site planning for power stations to enhance the landscape setting (Holford \& Shepherd, 1970). It's also shown at this point of time that the field was starting to shift from medical and health to computer science although some publications on dental office still appeared.

In 'Architecture' as early as the 1970s, there appeared a discussion on the issue of large complex building design in Nature suggesting programming and schematic design with computer-aided techniques (England, 1971). Computers began to enter the world of architecture and architects such as a paper entitled "Computer Programs for Architects and Layout Planners" (Lee 1971). This is a clear example of a call for the use of computer science as a tool for Architecture design. The object study, however, was still in the domain of medicine, namely the large complexes of hospitals.

Photogrammetry enters the domain of architecture describing the latest models of equipment used in architectural representation in the 1970s. Parameters of photogrammetric and stereometric cameras, plotting instruments, stereocomparators and image rectifiers are briefly discussed. There was also discussion on architecture in elderly, disabled and modern hospital design. On this type of building, numerous publications appeared addressing hospital, rehabilitation, airport medical facility, and dental office design including the topic of programming with systematic control and system approaches, management of planning, safety design, and ergonomics. There were also introductions to planning and design of tall buildings, the issue of environmental design and concerns towards ecology and nature in cities. Also within this range, there were articles that have high citations on the subject of acoustics in the Journal of the Acoustical Society of America, perceptions of space in the Scandinavian Journal of Psychology and the British Journal of Psychology as well as formulas of determining population from floor area ratio in the Journal of World Archaeology.

There was extensive use of coupling word such as software architecture, computer architecture, network architecture, as well as system architecture throughout the 1970s to 1990s. In the field of engineering, the Journal of Artificial Intelligence earned extensive attention showing huge numbers of citations. Many of them were addressing cognitive architecture. Special attention can be made to the work of Laird, J. E., Newell, A., \& Rosenbloom, P. S. (1987) that earned 1201 citations showing a system capable of general intelligent behavior. Special attention can be addressed to the Design Studies journal especially the work of Newland, P., Powell, J. A., \& Creed, C. (1987) delivering the idea of information handling and transfer for designers. They showed how designers perceive and learn about their world which is influenced by learning styles, perception, and culture. The paper earned 22 citations and perhaps marked the rise of how design and information are closely interrelated.

In the 2000s, computer science dominated in the use of architecture. In the middle of this new interaction, some significant keywords need attention. The first is the rising significance of the building information modeling (BIM) (138 articles). The big five of journals addressing BIM are the Automation in Construction (Elsevier), Journal of Construction Engineering (American Society of Civil Engineers), (Journal of Information Technology (Kungliga Tenkniska Hoegskolan/Royal Institute of Technology), Architectural Design (Wiley-Blackwell) and Journal of Computing in Civil Engineering (American Society of Civil Engineers (ASCE). From subject area composition, BIM covers the engineering side (78\%), computer science $(32.6 \%)$ and business management and accounting (13.0\%) with some new notions coming to the surface of discussions such as automation, collaboration platforms, supply chain integration, and performance modeling. The pace of this new 
approach reflects its significance as integration models of planning, design, construction, and operation as well as management of the facility in architecture, engineering, and construction (AEC) industry as reflected by Azhar's article (Azhar, 2011) that earns the 267 citations in this area. The notion of integration is even pushed forward into new integration through an autonomous assembly of collective production. This may replace old generic construction as indicated by Lu (2017) in Architectural Design. There is also concern on how the emerging subject areas of BIM and sustainability are being adopted in education including in distance learning, multidisciplinary collaboration, and industry collaborations as surveyed by Becerik-Gerber, B., Gerber, D. J., \& Ku, K. (2011).

An article that also earns attention in the potential of integration of BIM is gaming technology as outlined by Yan, W., Culp, C., \& Graf, R. (2011). The integration will open an entirely new form of Architecture as it merges places and buildings as physical dynamics with virtual environments and user activities in real-time interaction. Here the integration will be pushed forward into simulation and visualization, character modeling and animation, collision detection, navigation, path planning, materials lighting, and so on.

Another venue discussion is the rising notion of smart cities. There are over 660 articles addressing this new technology, rising drastically in the last five years (from 23 documents or less prior to 2012 to 149 in 2017). An article that earns attention is Zanella, A., Bui, N., Castellani, A., Vangelista, L., \& Zorzi, M. (2014) addressing the use of the Internet of things for smart cities. Smart city refers to a broad term of communication technologies supporting services for both the administration of a city and the citizens. Here the Internet of things covers various devices from the sensory level, network infrastructure to data management. This technology may transform the existing physical urban system to a hybrid cyber-physical new system as also outlined by Jin, J., Gubbi, J., Marusic, S., \& Palaniswami, M. (2014).

An entirely new way of using architecture is shown in the word nanoarchitecture that has developed in biochemistry and advanced material. The word addresses a way to build artificial nanostructures that can mimic biological systems and organs as outlined by Lin, C., Liu, Y., \& Yan, H. (2009). This article also earns considerable attention with 193 citations. Another use of architecture is on the advanced bioinspired or bio-mimetic composite as Studart, A. R. (2012) has outlined. Another article that shows the emerging scientific discipline of bio-mimetics in the field of Architecture is explored by Knippers, J., \& Speck, T. (2012) that earns 65 citations and appears in Bioinspiration and Biomimetics journal from IOP Publishing.

\section{Architech-in-formation: An Epilogue}

The above conversation between architecture and Architecture through literature exploration opens up a discussion on the ontological level of the current reality architectural discourse as Grosz has urged to pay attention to the outsideness of architecture. The above new realities push us - architecture scholar, educator, and architect - to not think of Architecture in the Pvesnerian or Vitruvian view anymore. The Pvesner duality of architecture as the conceptual value of Lincoln Cathedral as a piece of Architecture versus a bicycle shed as a building is no longer the standard. Indeed, our Vitruvian Architecture today is still very much alive but soon it will no longer be enough to contain the new wave of information technology marking the Industrial Revolution 4.0. What we are experiencing now is a radical disruption of Architecture. The concept of firmitas, durability of materials, has been pushed forward into biological forms that grow as well as self-assembly polymers for future building materials. The concept of function, utilitas, has also been pushed forward into new frontiers of the game. There will be no 'fixed' functional programs as the function itself will only be the result of continuous interaction between the cyber and the real. Convenience is not designed but programmed. The concept of beauty and delight, venustas, has also been transformed into stimulatory and transient qualities of beauty. Through this, we are not only filling a leftover space of Vitruvius's Ten Books of Architecture. It has become necessary to write another ten books of architectures for the modern era. Today, architecture is architecture-technology information as well as architecture information.

Regarding architectural education, what we face in Architectural Education 4.0 is not merely about the disruption of education created by massive open and online courses or the like, but rather the very essence of architecture itself. Architecture in formation will be about its materiality, its relational formation of human (and nonhuman) interactions with both its permanent and transient environment as well as its continuous manipulation of neural architecture for delight.

\section{References}

Asmaa AbuMezied. (n.d.). "The role of Higher Education in The Fourth Industrial Revolution." Retrieved October 18, 2017 , from https://www.weforum.org/agenda/2016/01/what-rolewill-education-play-in-the-fourth-industrial-revolution.

Azhar, S. (2011). "Building information modeling (BIM): Trends, benefits, risks, and challenges for the AEC industry." Leadership and Management in Engineering, 11(3), 241-252. doi:10.1061/(ASCE)LM.19435630.0000127.

Becerik-Gerber, B., Gerber, D. J., \& Ku, K. (2011). "The pace of technological innovation in architecture, engineering, and construction education: Integrating recent trends into the curricula." Electronic Journal of Information Technology in Construction, 16, 411-432. Retrieved from www.scopus.com.

England, R. (1971). "Planning complex building systems." Nature, 229 (5282), 233-236. doi:10.1038/229233a0.

Gad, R.K. 1961. "IV. The Office Environment-fact or Fancy." Journal of Occupational Medicine 3 (6).

Globus, G. G., \& Gilbert, J. (1964). "A Metapsychological Approach to the Architecture of Frank Lloyd Wright." Psychoanalytic Review, 51, 285-297. Retrieved from www.scopus.com.

Goldmann, Z. (1966). "The hospice of the Knights of St. John in Akko." Archaeology, 19(3), 182-189. Retrieved from www.scopus.com. 
Gottlieb, B.J. 1961. "Greek Gods of Medicine and Their Temples. II. Epidaurus: Impressions of a Study Trip to Hellas." Folia Clínica Internacional 11.

Grosz, E. (2001). Architecture from the Outside, Essays on Virtual and Real Space. Massachusetts London, England: The MIT Press Cambridge.

Holford WG, \& Shepheard HH. (1970). "Architect and power engineering." Electronics and Power, 16, 449-453. Retrieved from www.scopus.com.

Hutchings, A. (1960). "The Design of Housing." Royal Society of Health Journal 80.

Jin, J., Gubbi, J., Marusic, S., \& Palaniswami, M. (2014). "An information framework for creating a smart city through the Internet of things." IEEE Internet of Things Journal, 1(2), 112-121. doi:10.1109/JIOT.2013.2296516.

Knippers, J., \& Speck, T. (2012). "Design and construction principles in nature and architecture." Bioinspiration and Biomimetics, 7(1) doi:10.1088/1748-3182/7/1/015002.

Kolmovskoi, A.A. 1961. "Glass as a Hygienic Construction Material.” Gigiena I Sanitariia 26.

Laird, J. E., Newell, A., \& Rosenbloom, P. S. (1987). SOAR: An architecture for general intelligence. Artificial Intelligence, 33(1), 1-64. doi:10.1016/00043702(87)90050-6.

Leake, C.D. 1948. "Molecular Architecture of Cells." Federation Proceedings 7 (1).

Lee K. (1971). “Computer programs for architects and layout planners.” 139-147. Retrieved from www.scopus.com.

Lin, C., Liu, Y., \& Yan, H. (2009). "Designer DNA nanoarchitectures." Biochemistry, 48(8), 1663-1674. doi:10.1021/bi802324w.

Lu, A. (2017). "Autonomous assembly as the fourth approach to generic construction." Architectural Design, 87(4), 128-133. doi:10.1002/ad.2205.

Mayo Clinic History \& Heritage (n.d.). Retrieved October 18, 2017, from http://history.mayoclinic.org/timelines/history-

timeline.php and http://history.mayoclinic.org/toursevents/w-bruce-fye-center-for-the-history-ofmedicine.php.

Mongeon, P., \& Paul-Hus, A. (2015). "The Journal Coverage of Web of Science and Scopus: a Comparative Analysis." Https://arxiv.org/. Retrieved from https://arxiv.org/ftp/arxiv/papers/1511/1511.08096.pdf.

Mowrer, O.H. 1932. "A Note on the Effect of Re-peated Hypnotic Stimulation." Journal of Abnormal and Social Psychology 27 (1). doi:10.1037/h0071988.

Newland, P., Powell, J. A., \& Creed, C. (1987). 'Understanding architectural designers' selective information handling." Design Studies, 8(1), 2-16. doi:10.1016/0142-694X(87)90026-3.

Rowland, E.H. 1907. "A Further Application of a Result Obtained in Experimental Aesthetics." Psy-chological Review 14 (4). doi:10.1037/h0068206.

School Architecture. 1948. The Journal of the Royal Institute of Public Health and Hygiene 11 (7).
Snow, D. L. (1963). "Space Planning Principles for Biomedical Research Laboratories." Public Health Monograph, 71, 1-52. Retrieved from www.scopus.com.

Studart, A. R. (2012). "Towards high-performance bioinspired composites." Advanced Materials, 24(37), 5024-5044. doi:10.1002/adma.201201471.

UNESCO (n.d.). Sanctuary of Asklepios at Epidaurus. Retrieved October 18, 2017, from http://whc.unesco.org/en/list/491.

Wang, D., \& Groat, L. (2002). Architectural Research Methods. John Wiley \& Sons, Inc.

Yan, W., Culp, C., \& Graf, R. (2011). "Integrating BIM and gaming for real-time interactive architectural visualization." Automation in Construction, 20(4), 446458. doi:10.1016/j.autcon.2010.11.013.

Zanella, A., Bui, N., Castellani, A., Vangelista, L., \& Zorzi, M. (2014). "Internet of things for smart cities." IEEE Internet of Things Journal, 1(1), 22-32. doi:10.1109/JIOT.2014.2306328.

Ziemer, R. 1910. "Profile: Mayo Clinic Historical Suite and Archives." Watermark (Archivists and Librarians in the History of the Health Sciences) 33 (1). 